\title{
MAPEAMENTO DA DistribuiçÃo EsPaCial da INFESTAÇÃo DE Panicum maximum DURANTE A COLHEITA dA CUltura DE MILHO ${ }^{1}$
}

\author{
Mapping of the Spatial Distribution of Panicum maximum During Corn \\ Harvesting
}

\author{
SHIRATSUCHI, L.S. ${ }^{2}$, MOLIN, J.P. ${ }^{3}$ e CHRISTOFFOLETI, P.J. ${ }^{4}$
}

\begin{abstract}
RESUMO - Metodologias de mapeamento de plantas daninhas em áreas agrícolas estão sendo utilizados a fim de gerar mapas de aplicação localizada de herbicidas, sendo que, este mapeamento vem sendo feito através de ferramentas da agricultura de precisão. $\mathrm{O}$ mapeamento das plantas daninhas gera então mapas de tratamentos de herbicidas que comandam pulverizadores capazes de realizar a aplicação localizada de herbicidas, aproveitando o comportamento contagioso inerente da comunidade das plantas daninhas, porém poucos experimentos relatam a eficiência desses métodos. Este experimento teve como objetivo comparar metodologias de mapeamento do capim-colonião (Panicum maximum), com base na avaliação visual durante e após a colheita da cultura de milho. Durante a colheita foi conduzido o monitoramento com avaliação visual, feito por uma pessoa devidamente treinada e pelo operador antecipadamente orientado. Após a colheita, a avaliação visual foi feita por amostragens, numa grade regular de 20 × $20 \mathrm{~m}$. Foi observada uma subestimação de $6 \%$ da área infestada, com uma infestação de mais de $80 \%$ de cobertura pelo método de mapeamento durante a colheita, quando comparado com o caminhamento na grade regular após a colheita. Os dois métodos foram coincidentes em $45 \%$ da área marcada.
\end{abstract}

Palavras-chave: agricultura de precisão, capim-colonião, manejo localizado.

\begin{abstract}
Weed mapping methodologies are being tested in agricultural fields to generate maps of spotted application of herbicides by using precision farming tools. Weed mapping may generate herbicide treatment maps, allowing herbicide spray only where needed. However, few experiments have reported the efficiency of these methods. This research aimed to compare Panicum maximum mapping methodologies based on visual assessment during and after corn harvesting. Monitoring combined with visual assessment was performed during harvesting by a duly trained worker and a previously oriented operator. Visual assessment was done by samplings after harvesting in a regular $20 \times 20 \mathrm{~m}$ grid. An underestimation of $6 \%$ of the infested area was observed, with infestation over 80\%, by the mapping method during harvesting. The two methods were coincident in $45 \%$ of the area studied.
\end{abstract}

Key words: precision farming, weed mapping, site specific management.

1 Recebido para publicação em 4.2.2003 e na forma revisada em 18.6.2004.

Parte da dissertação de mestrado do primeiro autor.

2 Pesquisador em Agricultura de Precisão, Embrapa Cerrados, BR 020, Km 18, Caixa Postal 08223, 73301-970 Planaltina-DF, <shozo@ cpac.embrapa.br>. ${ }^{3}$ Prof. Dr., Departamento de Engenharia Rural da Escola Superior de Agricultura "Luiz de Queiroz" - ESALQ/USP; ${ }^{4}$ Prof. Dr., Departamento de Produção Vegetal - ESALQ/USP. 


\section{INTRODUÇÃO}

A infestação das plantas daninhas normalmente não ocorre de modo uniforme nas áreas agrícolas, sendo possivel o mapeamento de sua variabilidade espacial com a utilização de ferramentas da agricultura de precisão. Dessa forma, são possiveis aplicações de herbicidas de forma mais racional, quando comparada com pulverizações que se baseiam na média das infestações, sem considerar o grau de distribuição das plantas daninhas nas áreas.

Os métodos de mapeamento das plantas daninhas normalmente utilizados em outros países são: (i) amostragens sistemáticas em grade, que consiste na divisão da área em uma grade amostral, sendo avaliada a densidade das plantas daninhas para cada célula embora seja o método mais estudado e preciso, sua aplicação se restringe a áreas pequenas e experimentais, devido à dificuldade operacional (Lutman \& Perry, 1999); (ii) método de contorno das áreas de ocorrência, que é feito contornando as "reboleiras" das diferentes plantas daninhas dentro da área agrícola, gerando polígonos de infestações (Lass \& Callihan, 1993; Colliver et al., 1996); (iii) método linear, em que são feitas marcações de regiões de infestações durante o tráfego de máquinas ou outro tipo de operação dentro da área agrícola (Rew et al., 1996; Kvien et al., 1997); e (iv) sensoriamento remoto feito por avião, satélites e sensores acoplados aos pulverizadores, método este que apresenta como problemas as limitações da resolução dos equipamentos e o alto custo (Lutman \& Perry, 1999). Para Christensen et al. (1999), dentre todos os métodos disponiveis, ainda não existe um recomendado para mapeamento de grandes extensões agrícolas.

O mapeamento das plantas daninhas durante a colheita da cultura é atualmente a prática mais utilizada em áreas agrícolas dos Estados Unidos, pela sua facilidade metodológica, visto que aproveita a operação de colheita para realização do mapeamento, sendo possivel obter mapas pós-colheita que poderão servir de base para a safra seguinte (Lutman \& Perry, 1999). Trabalhos de pesquisa com plantas daninhas anuais evidenciam que a disseminação de sementes e plantas pela colhedora é um dos principais fatores que influem na localização de futuras "reboleiras", que são matematicamente previsiveis (Colliver et al., 1996).

O mapeamento da infestação da flora daninha durante a colheita da cultura consiste na marcação georreferenciada das "reboleiras" das plantas daninhas na operação de colheita. Durante o deslocamento da colhedora equipada com monitor de produtividade e GPS (Global Positioning System), o operador faz marcações quando entra e sai das "reboleiras" de plantas daninhas. Com a demarcação das passadas paralelas da colhedora e a posição de início e término desta demarcação, é determinada a região onde foi registrada a presença de determinada planta daninha (Colliver et al., 1996).

O objetivo deste experimento foi realizar o mapeamento - através de marcação georreferenciada - do capim-colonião (Panicum maximum) durante a operação de colheita do milho e compará-lo com o método de amostragens sistemáticas, para a obtenção de mapas de prescrição de herbicidas de manejo.

\section{MATERIAL E MÉTODOS}

O experimento foi conduzido em uma área de 8,5 ha, sob um pivô central que irrigava uma área total de 70 ha em sistema de plantio direto desde 1998. O solo predominante na área é a terra roxa estruturada eutrófica.

Foram feitos mapeamentos das plantas daninhas durante e após a colheita de milho (2000/2001), colhido na segunda quinzena de janeiro de 2001. O mapeamento após a colheita foi realizado no intuito de aferir o mapeamento feito durante a colheita do milho.

Foi utilizada uma colhedora John Deere, modelo STS 9650, equipada com monitor de produtividade Greenstar e DGPS (GPS com correção diferencial), que permitem a marcação de eventos como a ocorrência de plantas daninhas. O mapeamento durante a operação de colheita efetuado pelo operador da colhedora foi visual. O operador foi orientado a marcar áreas com mais de $80 \%$ de cobertura do terreno com a planta daninha especificada, segundo escala proposta por Harvey \& Wagner (1992). As marcações eram iniciadas quando a plataforma de corte da colhedora atingia a 
"reboleira" de alta infestação de capim-colonião e terminavam na saída da plataforma de corte das áreas com alta infestação de capim-colonião (Figura 1), proporcionando o mapeamento da localização das plantas daninhas.

Para comparar com o mapa de infestação gerado pelo operador da colhedora, foram realizadas marcações simultâneas por outra pessoa previamente treinada na identificação e atribuição de notas de infestações segundo a escala adotada (Harvey \& Wagner, 1992), utilizando um equipamento GPS portátil sem correção diferencial, no intuito de comparar com o mapa de infestação gerado pelo operador da colhedora. Foi considerada uma margem de segurança de posicionamento da infestação suficiente para o equipamento utilizado. Considerou-se que a área marcada tinha $20 \mathrm{~m}$ de largura de faixa infestada.

Os dados das marcações feitas pelo operador da colhedora foram separados dos demais dados originários do arquivo gerado pelo monitor de produtividade, como produtividade e umidade dos grãos e tempo, sendo previamente organizados no programa Excel e, em seguida, processados no software SSToolbox/ SST. Adotou-se um número arbitrário para os pontos onde foram marcadas as infestações altas do capim-colonião, sendo transformados em vários pontos com um mesmo valor, a fim de se obter uma seqüência de pontos formando as faixas de infestações ou flags. Por motivo de segurança, foi utilizada uma faixa de segurança ou buffer de 7,5 $\mathrm{m}$ de cada lado da linha de flag, com o objetivo de facilitar a comparação com o método de amostragens sistemáticas feito pelo caminhamento pós-colheita na grade de $20 \times 20 \mathrm{~m}$.

O mapeamento pelo método de amostragens sistemáticas após a colheita consistiu de um caminhamento em toda a área com um equipamento DGPS de mochila, registrando os dados de infestações numa grade de 20 × 20 m, predeterminada por um software de sistema de informações geográficas. O mapeamento foi feito anteriormente à pulverização do herbicida de manejo, ou seja, uma semana após a colheita. A distribuição da infestação das plantas daninhas foi georreferenciada por um receptor de DGPS acoplado a um computador portátil. Foram marcados somente os pontos georreferenciados com alta infestação $(80 \%$ de

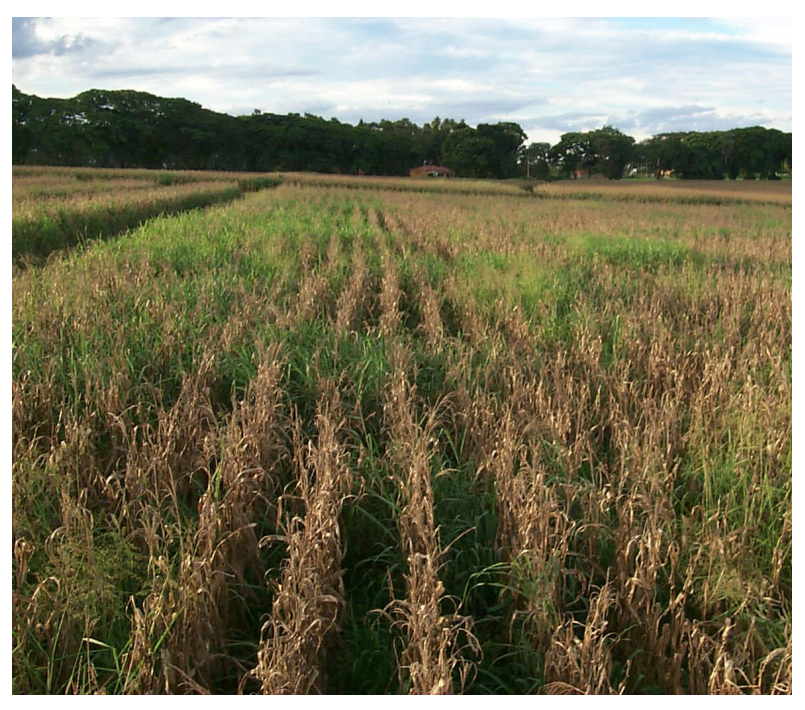

Figura 1 - Vista das reboleiras de alta infestação de capimcolonião (Panicum maximum) no momento da colheita.

cobertura) do capim-colonião, seguindo a mesma escala visual de cobertura do terreno adotada pelo método da colhedora. O caminhamento foi realizado uma semana após a colheita do milho, em janeiro de 2001, quando os danos causados ao capim-colonião durante a operação de colheita já haviam sido recuperados.

\section{RESULTADOS E DISCUSSÃO}

As marcações feitas pela pessoa que acompanhou o operador da colhedora com o equipamento GPS sem correção diferencial foram utilizadas para a geração do mapa de aplicação de herbicida de manejo, uma vez que, analisando os dados das marcações realizadas durante a colheita pelo operador da colhedora com o monitor de produtividade e o DGPS, constatou-se uma superestimação das áreas com mais de $80 \%$ infestação do capimcolonião, pois eventualmente o operador esquecia de desligar a marcação. Isso provavelmente se deve à complexidade dos diversos controles que o operador teve de manusear ao mesmo tempo. As marcações realizadas pelo operador foram desconsideradas no momento da avaliação do mapa, não sendo possivel fazer comparações entre as marcações feitas com o equipamento GPS sem diferencial e as realizadas pelo operador com DGPS. 
A porcentagem de cobertura da área com alta infestação do capim-colonião utilizando o equipamento GPS sem correção diferencial foi de $26 \%$, enquanto pelo método de amostragens sistemáticas após a colheita foram observados $32 \%$ da área total com $80 \%$ de infestação. Dessa forma, o mapeamento durante a colheita utilizando GPS subestimou em 6\% a área com alta infestação, em comparação com o método de amostragens sistemáticas (Tabela 1).

O total de pontos com alta infestação do capim-colonião através do método de amostragem sistemática foi de 69 , enquanto os obtidos pelo avaliador durante a colheita foram de 56. O número de marcações coincidentes entre os métodos foi de 32, representando 45\% de pontos coincidentes (Figura 2).

Resultados diferentes entre métodos de amostragens de áreas infestadas por plantas daninhas também foram obtidos por Colliver et al. (1996), no mapeamento da cobertura do terreno por Avena fatua em função da presença desta durante a colheita, fazendo comparações com o método de amostragens sistemáticas numa grade de $5 \times 10 \mathrm{~m}$ e com o método de contorno das áreas de ocorrência. Numa área foram determinadas infestações em $61 \%$ da área em marcações feitas durante a colheita, em $42 \%$ pelo método de amostragem sistemática em grade e em 43\% pelo método de contorno das "reboleiras", com coincidência de $27 \%$ entre os três métodos. Em uma outra área foram obtidos $90 \%$ de cobertura com a planta daninha para marcações feitas durante a colheita, $69 \%$ em amostragem sistemática em grade e $67 \%$ pelo método de contorno das reboleiras de infestação, com uma área comum aos três métodos de $56 \%$.

Tabela 1 - Área de infestação com mais de 80\% de cobertura de capim-colonião (Panicum maximum), porcentagem da área com alta infestação e tempo utilizado para levantamento da área após a colheita do milho

\begin{tabular}{|l|c|c|c|c|}
\hline Metodologia & $\begin{array}{c}\text { Área total } \\
\text { (ha) }\end{array}$ & $\begin{array}{c}\text { Área - alta infestação } \\
\text { (ha) }\end{array}$ & $\begin{array}{c}\text { Porcentagem da área } \\
\text { com alta infestação }\end{array}$ & $\begin{array}{c}\text { Tempo gasto } \\
\text { (horas) }\end{array}$ \\
\hline Amostragem sistemática & 8,5 & 2,76 & 32 & 4 \\
\hline Colheita georreferenciada & 8,5 & 2,24 & 26 & *N. \\
\hline
\end{tabular}

* Não-determinado.

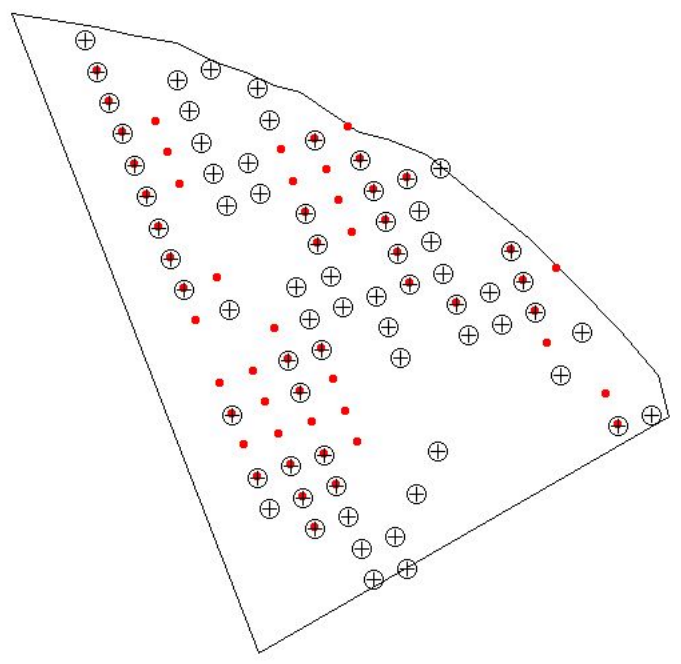

Área experimental
Amostragens sistemáticas para aferição

$\oplus \quad$ Alta infestação

Marcações durante a colheita

- Alta infestação

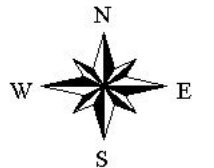

Figura 2 - Mapa das marcações de alta infestação de capim-colonião feitas durante e após a colheita do milho. 
Pela disponibilidade dos dados das áreas com alta infestação de capim-colonião nesta área, realizou-se o mapeamento pelo contorno das áreas de ocorrência; contudo, como a área possuía infestação alta do capim-colonião $(80 \%$ de cobertura), não foi possivel a distinção das "reboleiras". Da mesma forma, Stafford et al. (1996) obtiveram também resultados comprovando que, para este tipo de mapeamento, a dificuldade é de se contornar uma "reboleira", pois isso depende do nivel de infestação, do grau de contagiosidade e do tipo de planta estudada, além de ser muito difícil a distinção dos limites entre elas.

A amostragem sistemática em grade determinou 24 pontos adicionais de alta infestação não marcados durante a colheita, ou seja, aproximadamente um hectare a mais foi considerado com alta infestação, os quais não foram marcados durante a colheita. Da mesma forma, foram marcados 23 pontos considerados de alta infestação durante a colheita, que não foram considerados de alta infestação pelo método de amostragem sistemática em grade. A amostragem sistemática da área experimental de 8,5 ha demorou cerca de quatro horas, visto que se buscava uma grande adequação à escala visual utilizada como referência (Tabela 1 ).

A importância da determinação da real infestação nas áreas de cultivo para a aplicação de herbicida na dose necessária é evidente, pois os resultados mostraram que somente $32 \%$ da área foi considerada com alta infestação pelo método de amostragem sistemática em grade; portanto, se fosse realizada uma pulverização de qualquer herbicida na forma convencional em área total, tomando por base as regiões de alta infestação, nos $68 \%$ restantes da área com infestações menores teria sido utilizada dosagem desnecessária de herbicida. Por outro lado, se o referencial fosse a área de menor infestação, os 32\% de alta infestação poderiam não ser suficientemente controlados com o herbicida de manejo. Também, o mapeamento qualitativo das infestações de plantas daninhas, em vez de contagem de plântulas jovens, pode ser adotado, devido à sua praticidade e rapidez. Para Medlin $\&$ Shaw (2000), economias consideráveis de herbicidas podem ser conseguidas não somente pela nãoutilização, mas também pela melhor alocação das doses dentro do sistema de produção agrícola.

Os resultados permitiram inferir que a metodologia avaliada durante a operação de colheita não foi capaz de identificar alguns pontos de alta infestação detectados pela amostragem sistemática em grade. Considerando como referência a grade de $20 \times 20 \mathrm{~m}$, foram subestimados alguns pontos considerados de alta infestação.

O mapeamento obtido por avaliação visual durante a colheita obteve correlação de $45 \%$ quando comparado com a amostragem sistemática na grade de referência.

Apesar dos problemas observados no mapeamento da infestação durante a colheita utilizando-se monitores de produtividade com opção de registro de outros eventos, como flags (marcações das plantas daninhas durante a colheita), esta metodologia de mapeamento de plantas daninhas apresenta grande potencial de uso na agricultura, por não exigir exclusividade de execução, uma vez que ela é realizada concomitantemente com a colheita monitorada, e pela facilidade de execução em relação aos outros métodos utilizados até o momento.

\section{AGRADECIMENTOS}

Aos Departamentos de Engenharia Rural e Produção Vegetal da ESALQ/USP, pelos equipamentos e softwares utilizados, e à Fundação de Amparo à Pesquisa do Estado de São Paulo (FAPESP), pelo auxílio.

\section{LITERATURA CITADA}

CHRISTENSEN, S.; WALTER, A. M.; HEISEL, T. The patch treatment of weeds in cereals. In: THE 1999 BRIGHTON CONFERENCE - WEEDS, Brighton, 1999. Proceedings... Brighton: BCPC, 1999. p. 591-600.

COLLIVER, C. T. et al. Georeferencing wild oat infestations in small grains: Accuracy and efficiency of three weed survey techniques. In: INTERNATIONAL CONFERENCE ON PRECISION AGRICULTURE, 3., 1996, Minneapolis. Proceedings... Wisconsin: ASA, 1996. p. 453-463.

HARVEY R G.; WAGNER C. R. A simple technique for predicting future weed problems. Madison: Nutrient and Pest Management Program, University of Wisconsin, 1992. 3 p. (Cooperative Extension Division). 
KVIEN, C. K.; BOYDELL, C. D.; POCKNEE, S. Precision management of spatially variable weeds. In: THE EUROPEAN CONFERENCE ON PRECISION AGRICUlturE, 1., 1997, Warwick. Proceedings... Oxford: BIOS Scientific, 1997. p. 983-989.

LASS, L. W.; CALLIHAN, R. H. GPS and GIS for weed surveys and management. Weed Technol., v. 7, n. 1, p. 249 $-254,1993$.

LUTMAN, P. J. W.; PERRY, N. H. Methods of weed patch detection in cereal crops. In: THE 1999 BRIGHTON CONFERENCE - WEEDS, Brighton, 1999a.

Proceedings... Brighton: BCPC, 1999. p. 627-634.
MEDLIN, C. R.; SHAW, D. R. Economic comparison of broadcast and site specific applications in nontransgenic and glyphosate-tolerant Glycine max. Weed Sci., v. 48, p. 653661, 2000.

REW, L. J. et al. A technique for mapping the spatial distribution of Elymus repens with estimates of the potential reduction in herbicides usage from patch spraying. Weed Res., v. 36, p. 283-292, 1996.

STAFFORD, J. V.; LeBARS, J. M.; AMBLER, B. A hand held data logger with integral GPS for producing weed maps by field walking. Comp. Elect. Agric., v. 14, n. 2/3, p. 235247, 1996. 